\title{
RESEARCH
}

Open Access

\section{Role of MCP-1 and CCR2 in ethanol-induced neuroinflammation and neurodegeneration in the developing brain}

Kai Zhang, Haiping Wang, Mei Xu, Jacqueline A. Frank and Jia Luo* (B)

\begin{abstract}
Background: Neuroinflammation and microglial activation have been implicated in both alcohol use disorders (AUD) and fetal alcohol spectrum disorders (FASD). Chemokine monocyte chemoattractant protein 1 (MCP-1) and its receptor C-C chemokine receptor type 2 (CCR2) are critical mediators of neuroinflammation and microglial activation. FASD is the leading cause of mental retardation, and one of the most devastating outcomes of FASD is the loss of neurons in the central nervous system (CNS). The underlying molecular mechanisms, however, remain unclear. We hypothesize that MCP-1/CCR2 signaling mediates ethanol-induced neuroinflammation and microglial activation, which exacerbates neurodegeneration in the developing brain.
\end{abstract}

Methods: $\mathrm{C} 57 \mathrm{BL} / 6$ mice and mice deficient of $\mathrm{MCP}-1\left(\mathrm{MCP}^{-1^{-/-}}\right)$and $\mathrm{CCR} 2\left(\mathrm{CCR} 2^{-/-}\right)$were exposed to ethanol on postnatal day 4 (PD4). Neuroinflammation, and microglial activation, and neurodegeneration in the brain were evaluated by immunohistochemistry and immunoblotting. A neuronal and microglial co-culture system was used to evaluate the role of microglia and MCP-1/CCR2 signaling in ethanol-induced neurodegeneration. Specific inhibitors were employed to delineate the involved signaling pathways.

Results: Ethanol-induced microglial activation, neuroinflammation, and a drastic increase in the mRNA and protein levels of MCP-1. Treatment of Bindarit (MCP-1 synthesis inhibitor) and RS504393 (CCR2 antagonist) significantly reduced ethanolinduced microglia activation/neuroinflammation, and neuroapoptosis in the developing brain. $\mathrm{MCP}_{-1}{ }^{-/-}$and $\mathrm{CCR2}^{-/-}$ mice were more resistant to ethanol-induced neuroapoptosis. Moreover, ethanol plus MCP-1 caused more neuronal death in a neuron/microglia co-culture system than neuronal culture alone, and Bindarit and RS504393 attenuated ethanol-induced neuronal death in the co-culture system. Ethanol activated TLR4 and GSK3 $\beta$, two key mediators of microglial activation in the brain and cultured microglial cells (SIM-A9). Blocking MCP-1/CCR2 signaling attenuated ethanol-induced activation of TLR4 and GSK3ß.

Conclusion: MCP-1/CCR2 signaling played an important role in ethanol-induced microglial activation/neuroinflammation and neurodegeneration in the developing brain. The effects may be mediated by the interaction among MCP-1/CCR2 signaling, TLR4, and GSK3 $\beta$.

Keywords: Alcohol abuse, Apoptosis, Chemokines, Development, Glia, Neurodegeneration

\footnotetext{
* Correspondence: jialuo888@uky.edu

Department of Pharmacology and Nutritional Sciences, University of Kentucky

College of Medicine, 132 Health Sciences Research Building, 1095 Veterans

Drive, Lexington, KY 40536, USA
}

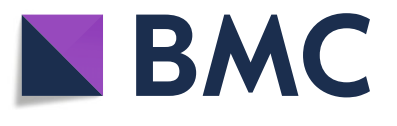

(c) The Author(s). 2018 Open Access This article is distributed under the terms of the Creative Commons Attribution 4.0 International License (http://creativecommons.org/licenses/by/4.0/), which permits unrestricted use, distribution, and reproduction in any medium, provided you give appropriate credit to the original author(s) and the source, provide a link to the Creative Commons license, and indicate if changes were made. The Creative Commons Public Domain Dedication waiver (http://creativecommons.org/publicdomain/zero/1.0/) applies to the data made available in this article, unless otherwise stated. 


\section{Background}

Fetal alcohol spectrum disorders (FASD) are a spectrum of defects that can present as physical, mental, and $\backslash$ or behavioral disabilities that stem from ethanol exposure during fetal development. FASD is estimated to affect as many as $2-5 \%$ of the population and costs the USA more than $\$ 5$ billion annually [1]. One of the most devastating effects of developmental exposure to ethanol is the permanent loss of neurons in the central nervous system (CNS) [2, 3]. Although significant progress has been achieved in this line of research, the underlying molecular mechanisms remain unclear. Ethanol-induced neuronal death is accompanied by microglial activation and neuroinflammation [4-7]. Monocyte chemoattractant protein 1 (MCP-1), also called chemokine (CC motif) ligand 2 (CCL2), is a key chemokine involved in neuroinflammation [8-10]. In mouse and human brain, MCP-1 and its receptor CCR2 are primarily expressed by microglia [8]. Although inflammatory response represents one of the first immune processes that protect an organism against diseases following injury, prolonged and sustained inflammation may have cytotoxic effects, aggravating the incidence and the severity of the disease. Increased MCP-1 expression and microglial activation have been observed in the brain of human alcoholics [11]. It has been hypothesized that ethanol exposure may sensitize the immune system to subsequent insults and lead to excess neuroinflammation in alcohol use disorders (AUD) and FASD $[12,13]$. It is also proposed that microglia primed by ethanol exposure may contribute to neurotoxicity observed in AUD and FASD [12, 13]. Elevated MCP-1 levels have been observed in brains which undergo various pathogenesis processes, such as multiple sclerosis [14, 15], stroke [16, 17], and Alzheimer's disease patients $[18,19]$, and it is believed that the upregulation of $\mathrm{MCP}-1$ is involved in the progression of these diseases $[15,16,19]$. Interestingly, the detrimental effects caused by overexpression of MCP-1 in those diseases were not observed in mice lacking CCR2 [20-23]. Therefore, MCP-1/CCR2 signaling may play an important role in neuroinflammatory diseases. In this study, we sought to determine whether MCP-1/CCR2 signaling is involved in ethanol-induced microglial activation and neuroinflammation in the context of neurodegeneration in the developing brain. We used a well-established third trimester equivalent mouse model in which ethanol exposure caused wide spread neurodegeneration. We showed that inhibiting MCP-1/CCR2 signaling significantly reduced ethanol-induced microglial activation/neuroinflammation and ameliorated neurodegeneration in the developing brain. It appeared that ethanol-induced microglial activation/neuroinflammation was mediated by the interaction among MCP-1/CCR2 signaling, TLR4, and GSK3 3 .

\section{Methods}

\section{Reagents}

Bindarit, an inhibitor of MCP-1 synthesis, was purchased from Cayman chemical (Ann Arbor, MI, USA). CCR2 antagonist RS504393 was purchased from TOCRIS, Inc. (Minneapolis, MN, USA). TLR4 inhibitor TAK242 was purchased from EMD Millipore, Inc. (Burlington, MA, USA). GSK3 $\beta$ inhibitor SB-216763 was purchased from Sigma-Aldrich, Inc. (St. Louis, MO, USA). Anti-MCP-1 antibody was purchased from Bio-Rad AbD Serotec, Inc. (Raleigh, NC, USA). Anti-CCR-2 antibody was purchased from BioVision, Inc. (Milpitas, CA, USA). Anti-Iba-1 antibody was purchased from Wako Chemicals USA, Inc. (Richmond, VA, USA). All other antibodies were purchased from Cell Signaling Technology, Inc. (Beverly, MA, USA). Other chemicals/reagents used in this project were obtained from Thermo Fisher Scientific, Inc. (Waltham, MA, USA) unless stated otherwise.

\section{Animals and ethanol exposure}

C57BL/6J mice were obtained from Jackson Laboratory (Bar Harbor, ME, USA). C57BL/6 mice, ${\mathrm{MCP}-1^{-/}}^{-}$ (B6.129S4-Ccl2 $\left.2^{\mathrm{tm} 1 \mathrm{Rol}} / \mathrm{J}\right)$, and CCR2 ${ }^{-/-}$(B6.129S4-Ccr2 $\left.{ }^{\mathrm{tm} 1 \mathrm{Ifc}} / \mathrm{J}\right)$ mice were obtained from Jackson Laboratories (Bar Harbor, ME, USA). All animals were housed in a specific pathogen-free room within the animal facilities at the University of Kentucky, and handled according to the Institutional Animal Care and Use Committee (protocol \#: 2008-0401).

Postnatal day 4 (PD4) mouse pups of either sex from six litters were weighed, and randomly assigned to one of six groups: control, ethanol (EtOH), Bindarit, RS504393, EtOH plus Bindarit, and $\mathrm{EtOH}$ plus RS504393. Pups received a total of $5 \mathrm{~g} / \mathrm{kg}$ ethanol in two subcutaneous (SC) injections which were $2 \mathrm{~h}$ apart; each contained ethanol $(2.5 \mathrm{~g} / \mathrm{kg}, 20 \%$ solution in saline) [24, 25]. We have previously determined that the blood alcohol concentration (BAC) was $338 \mathrm{mg} / \mathrm{dl} 8 \mathrm{~h}$ after the first injection [25]. BACs greater than $300 \mathrm{mg} / \mathrm{dl}$ are not uncommon in human alcoholics [26-29]. Some alcoholics with a BAC $>400 \mathrm{mg} / \mathrm{dl}$ were coherent and able to drive [29]. BACs $>500 \mathrm{mg} / \mathrm{dl}$ have been reported in heavy drinkers [27, 28, 30]. Bindarit is an inhibitor of MCP-1 synthesis and RS504393 is an antagonist for CCR2; they have been extensively used to block MCP-1/ CCR2 signaling in vitro and in vivo [31, 32]. Bindarit $(100 \mathrm{mg} / \mathrm{kg})$ or $\mathrm{RS} 504393(1 \mathrm{mg} / \mathrm{kg})$ were administered by two subcutaneous (SC) injections at 24 and $0.5 \mathrm{~h}$ prior to ethanol exposure. The concentrations of Bindarit and RS504393 used in this study were based on previous publications [31, 32]. The control pups received an injection of equal volume of saline or DMSO, depending on whether it was an inhibitor or ethanol exposure. At $8 \mathrm{~h}$ after the first ethanol injection, pups were 
sacrificed and the brains were dissected and processed for further analysis. A diagram showing the paradigm of ethanol and inhibitor administration is demonstrated (Fig. 1).

\section{Culture of microglial cells and neurons}

Immortalized mouse microglia cells (SIM-A9) were purchased from American Type Culture Collection (ATCC) (Manassas, VA, USA). SIM-A9 cells are a spontaneously immortalized microglial cell line that exhibits key characteristics of cultured primary microglia [33]. SIM-A9 cells were maintained in Dulbecco's modified Eagle's medium (DMEM)/F12 medium supplemented with 5\% horse serum, 10\% fetal bovine serum (FBS), $2 \mathrm{mM} \mathrm{L-glu-}$ tamine, $100 \mathrm{U} / \mathrm{ml}$ penicillin, and $100 \mu \mathrm{g} / \mathrm{ml}$ streptomycin at $37{ }^{\circ} \mathrm{C}$ in $5 \% \mathrm{CO}_{2}$ in a humidified atmosphere. The culture medium was replaced with DMEM/F12 medium without FBS at $50-60 \%$ confluence overnight before indicated treatment. The cultures were exposed to ethanol $(0.2,0.4$, or $0.8 \%)$ in sealed containers. The containers were placed in a humidified environment and maintained at $37{ }^{\circ} \mathrm{C}$ with $5 \% \mathrm{CO}_{2}$. Using this method, the ethanol concentration in the culture medium can be accurately maintained [34]. To block MCP-1/CCR2 signaling, SIM-A9 cells were exposed to Bindarit $(300 \mu \mathrm{M})$ or RS504393 $(100 \mu \mathrm{M})$ for $12 \mathrm{~h}$ prior to ethanol treatment. The concentrations of Bindarit and RS504393 were based on previous publications [35, 36]. To block TLR4 or GSK3 $\beta$ signaling, SIM-A9 cells were exposed to TAK242 $(1 \mu \mathrm{M})$ or SB $216763(10 \mu \mathrm{M})$ for $12 \mathrm{~h}$ prior to ethanol treatment. The concentrations of TAK242 and SB 216763 were based on previous studies [37, 38]. Primary cortical and cerebellar neurons were generated from the brain of C57BL6 mice on postnatal day 1. The methods for the isolation and culture of primary cortical and cerebellar neurons have been previously described in detail $[39,40]$. Briefly, the pups were decapitated, and the brain immediately transferred into dissection medium (97.5\% Hank's balanced salt solution, $0.11 \mathrm{mg} /$ $\mathrm{ml}$ sodium pyruvate, $0.1 \%$ glucose, $10 \mathrm{mM}$ HEPES, $100 \mathrm{U} / \mathrm{ml}$ penicillin, and $100 \mu \mathrm{g} / \mathrm{ml}$ streptomycin). The meninges were removed, and the cerebral cortices and cerebella dissected. Cerebral cortical tissues and cerebella were dissociated with $0.25 \%$ trypsin followed by $0.1 \%$ DNase treatment. Then, tissues were carefully triturated, and the cell suspension was mixed with $4 \%$ bovine serum albumin and centrifuged. The cell pellet was resuspended in Neurobasal/B27 medium containing B27 (2\%), glutamine $(1 \mathrm{mM} / \mathrm{L})$, penicillin $(100 \mathrm{U} / \mathrm{ml})$, and streptomycin $(100 \mu \mathrm{g} / \mathrm{ml})$. Cells were plated onto poly-D-lysine $(50 \mu \mathrm{g} / \mathrm{ml})$-coated cell culture plates. The co-cultures of microglia cells and primary cortical neurons or cerebellar neurons were established in 24-well cell culture plates with inserts as described previously [41]. The cortical or cerebellar neurons were maintained in the cell culture plate containing $500 \mu \mathrm{l}$ of medium at a density of $4 \times 10^{6}$ cells/well. SIM-A9 cells were grown in a Falcon ${ }^{\text {Tm }}$ Cell Culture Insert $(1 \mu \mathrm{m}$ pore size, Cat\#: C353104) in a separate plate at a density of $1 \times 10^{6}$ cells/ per insert in $200 \mu \mathrm{l}$ of medium overnight at $37^{\circ} \mathrm{C}$ and $5 \% \mathrm{CO}_{2}$, then treated with Bindarit $(300 \mu \mathrm{M})$ or RS504393 $(100 \mu \mathrm{M})$ for $12 \mathrm{~h}$. After that, the inserts containing SIM-A9 cells were placed into the wells containing the cortical neurons or cerebellar neurons. The co-cultures were then treated with ethanol for $48 \mathrm{~h}$. The viability of neurons was determined by a 3-(4,5-dimethyl-thiazol-2-yl)-2,5-diphenyltetrazolium bromide (MTT) assay as previously described [40].

\section{Immunoblotting}

After treatment, mice were anesthetized by intraperitoneal injection of ketamine/xylazine, and the cerebral cortices and cerebella were immediately dissected. The tissue was frozen in liquid nitrogen and stored at $-80^{\circ} \mathrm{C}$. The protein from brain tissue or SIM-A9 cells were extracted and processed for immunoblotting (IB) as previously described [40]. Briefly, tissues or cells were homogenized in an ice cold lysis buffer containing $50 \mathrm{mM}$ Tris- $\mathrm{HCl}(\mathrm{pH} 7.5)$, $150 \mathrm{mM} \mathrm{NaCl}, 1 \mathrm{mM}$ EGTA, 0.5\% NP-40, 0.25\% SDS, $1 \mathrm{mM}$ PMSF, $5 \mu \mathrm{g} / \mathrm{ml}$ leupeptin, and $5 \mu \mathrm{g} / \mathrm{ml}$ aprotinin. Homogenates were centrifuged at 20,000 g for $30 \mathrm{~min}$ at $4{ }^{\circ} \mathrm{C}$, and the supernatant fraction was collected. Aliquots of the protein samples were separated on a SDS-polyacrylamide gel by electrophoresis. The separated proteins were transferred to nitrocellulose membranes. The membranes were probed with primary antibodies overnight at $4{ }^{\circ} \mathrm{C}$. The immune complexes were detected by the enhanced chemiluminescence substrate (GE Healthcare, Chalfont, Buckinghamshire, UK). The density of immunoblotting was quantified with the software of Image lab 5.2 (Bio-Rad Laboratories, Hercules, CA, USA).

Fig. 1 Paradigm for ethanol and inhibitor administration. Mouse pups received two subcutaneous (SC) injections of ethanol which were $2 \mathrm{~h}$ apart;
each contained ethanol (2.5 $\mathrm{g} / \mathrm{kg}, 20 \%$ solution in saline). Bindarit (100 $\mathrm{mg} / \mathrm{kg})$ or RS504393 (1 $\mathrm{mg} / \mathrm{kg})$ was administered by two SC injections at 24
and $0.5 \mathrm{~h}$ prior to the first ethanol exposure




\section{Quantitative real-time RT-PCR}

After ethanol treatment, mice were decapitated and the cortex was quickly frozen in liquid nitrogen and then stored in $-80{ }^{\circ} \mathrm{C}$ until use. Total RNA was isolated using TRIZOL reagent (Invitrogen) according to the manufacturer's instructions. $1 \mu \mathrm{g}$ of total RNA was used for first strand cDNA synthesis (Promega, A3500). Quantitative real-time RT-PCR was performed on a Lightcycler 480 system (Roche) using a Power SYBR Green PCR Master kit (Invitrogen, 4368706) with cDNA and primers $(1 \mu \mathrm{M})$ according to the manufacturer's recommendation. The primers used for analysis were as follows: CCR2 forward 5'-GGTCATGATCCCTATGTGG-3'. CCR2 reverse 5' -C TGGGCACCTGATTTAAAGG-3'. MCP-1 forward 5' -C TTCTGGGCCTGCTGTTCA-3'. MCP-1 Reverse 5' -CA GCCTACTCATTGGGATCA-3'. After finishing the last cycle, a melting curve analysis was performed. Standard $-\Delta \Delta$ Ct method was used for determining the gene expression.

\section{Immunohistochemistry and determination of activated microglia}

The procedure for immunohistochemistry (IHC) has been previously described [42]. Briefly, the pups were decapitated and the brain tissues were removed, post fixed in $4 \%$ paraformaldehyde for $24 \mathrm{~h}$ and then transferred to $30 \%$ sucrose in PBS until the brain sunk to the bottom. Sagittal brain sections $(20-40 \mu \mathrm{m})$ were cut on a freezing microtome. Floating sections were permeabilized with $0.1 \%$ Triton X-100 in PBS and incubated in $0.3 \% \mathrm{H}_{2} \mathrm{O}_{2} / 50 \%$ methanol in PBS and then mounted on slides and dried. The slides were blocked with 5\% normal goat serum containing $0.5 \%$ Triton X-100 in PBS at room temperature, and then incubated with primary antibodies (diluted in PBS with $1 \%$ BSA) overnight at $4{ }^{\circ} \mathrm{C}$. The dilution for the primary antibodies was anti-cleaved caspase-3 antibody, 1:600; anti-Iba1 antibody, 1:600. After washing with PBS, slides were incubated with a biotin-conjugated goat anti-rabbit secondary antibody (1:1000) for $1 \mathrm{~h}$ at room temperature and then washed with PBS. Avidin-biotin-peroxidase complex was prepared according to the manufacturer's instructions. The slides were incubated in the complex for $1 \mathrm{~h}$ at room temperature. After rinsing, the slides were developed in $0.05 \%$ 3, 3'-diaminobenzidine (DAB) containing $0.003 \%$ $\mathrm{H}_{2} \mathrm{O}_{2}$ in PBS.

Iba-1 IHC has been extensively used to identify microglia. Activated microglia were determined morphologically. The resting microglia exhibit long branching processes and a small cellular body, while the activated microglia have fewer but thicker processes with a larger cell body [43]. The average numbers of activated Iba-1-positive cells and all Iba-1-positive cells were calculated from three randomly selected microscopic fields, and three consecutive sections were analyzed for each brain.

\section{Fluoro-Jade C staining}

Fluoro-Jade $\mathrm{C}$ is a sensitive fluorescent marker for degenerating neurons. The procedure for Fluoro-Jade $\mathrm{C}$ staining has been previously described in detail [44]. Briefly, frozen slides of brain tissue were prepared at a thickness of $10 \mu \mathrm{m}$ and first immersed in a basic alcohol solution consisting of $1 \%$ sodium hydroxide in $80 \%$ ethanol. They were then rinsed in $70 \%$ ethanol and incubated in $0.06 \%$ potassium permanganate solution. Slides were then transferred to a $0.0001 \%$ solution of Fluoro-Jade C (Chemicon, Temecula, CA, USA), dissolved in $0.1 \%$ acetic acid vehicle. The slides were then rinsed with distilled water. The air-dried slides were then cleared in xylene for at least $1 \mathrm{~min}$ and then cover slipped with DPX (Sigma) non-fluorescent mounting media. The slides were examined and recorded with a fluorescent microscope (IX81, Olympus).

\section{Statistical analysis}

The data were presented as mean \pm SEM. Statistical significance was determined by the ANOVA followed by Tukey's post hoc test. Differences in which $p$ was $<0.05$ were considered statistically significant.

\section{Results}

Ethanol increases MCP-1 expression in the developing brain and cultured microglial cells

Ethanol exposure increases the expression MCP-1 in the adult brain of mice and human alcoholics [11, 45]. To evaluate the role of MCP-1/CCR2 in ethanol-induced damage in the developing brain, we first sought to determine the effect of ethanol on MCP-1/CCR2 expression in the developing brain. Using a well-established mouse model of postnatal ethanol exposure [2, 24, 25], we showed that ethanol increased MCP-1 expression but not CCR2 in the brain of postnatal day 4 (PD4) mice (Fig. 2a). Ethanol also upregulated MCPIP, a downstream effector of MCP-1/CCR2 signaling. Consistently, ethanol increased mRNA levels of MCP-1 but not CCR2 (Fig. 2b). Since microglia are the major source of MCP-1, we examined the effect of ethanol on a cultured microglial cell line (SIM-A9). Ethanol drastically increased the expression of MCP-1 but not CCR2 in SIM-A9 cells (Fig. 2c).

\section{Bindarit and RS504393 block ethanol-induced caspase-3 activation in the developing brain}

In this model of postnatal ethanol exposure, ethanol caused a wide-spread neuroapoptosis in the developing brain, which was indicated by the expression of cleaved caspase-3 [2, 24, 25]. As shown in Fig. 3, a significant 

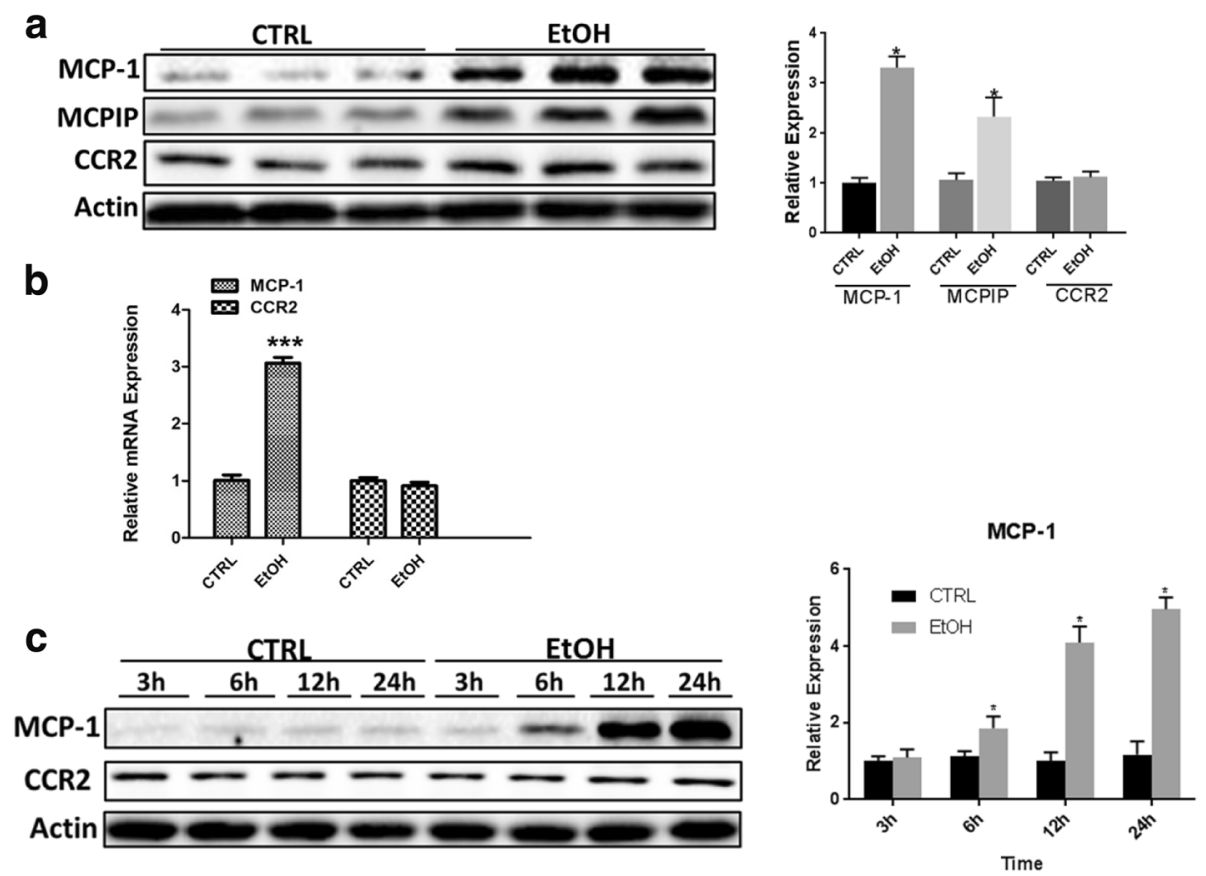

Fig. 2 Effect of ethanol on MCP-1 and CCR2 expression. a C57BL6 mice of postnatal day 4 (PD4) were exposed to ethanol (EtOH) as described in the "Methods" section. $8 \mathrm{~h}$ after EtOH exposure, mice were sacrificed and the brain was processed for immunoblotting (IB) analysis of MCP-1 and CCR2. The expression of MCP-1, MCPIP, and CCR2 in the brain was quantified and normalized to actin. Each data point was the mean \pm SEM of six animals. b The expression of MCP-1 and CCR2 mRNA in the brain was determined by quantitative RT-PCR as described in the "Methods" section. Each data point was the mean \pm SEM of three animals. ${ }^{* * *} p<0.001$, statistically significant difference from control group. c SIM-A9 cells were exposed to EtOH ( $0.4 \%$ for $3,6,12$, or $12 \mathrm{~h}$. The expression of MCP-1 and CCR2 was determined by IB and quantified by the normalization to the expression of actin. Each data point was the mean \pm SEM of three independent experiments. ${ }^{*} p<0.05$, statistically significant difference from control group

alteration in cleaved caspase- 3 was observed in the cortex $[\mathrm{F}(5,30)=59.56 ; p \leq 0.05]$ and cerebellum $[\mathrm{F}(5,30)=48.18$; $p \leq 0.05$ ]. Ethanol increased the expression of cleaved caspase-3 in the cerebral cortex and cerebellum. Bindarit or RS504393 treatment significantly decreased ethanol-induced caspase- 3 activation. There was little caspase- 3 activation in the saline-injected controls and in Bindarit- or RS504393-treated groups.

\section{$\mathrm{MCP}^{-1}{ }^{-/-}$and $\mathrm{CCR2}^{-/-}$mice are more resistant to ethanol neurotoxicity}

To verify the study using MCP-1 and CCR2 inhibitors, we compared ethanol-induced neuroapoptosis in the cortex and cerebellum among wild-type (WT), MCP-1 ${ }^{-1}$ - mice, and CCR2 ${ }^{-/-}$mice. As shown in Fig. 4, ethanol increased the expression of cleaved caspase- 3 in the cortex and cerebellum of WT mice; ethanol also increased the expression of cleaved caspase- 3 in $\mathrm{MCP}-1^{-/-}$mice and CCR2 $2^{-1-}$ mice, but to a much lesser extent (Fig. 4a). It appeared that deletion of MCP-1 was more effective than CCR2 in terms of protective effects (Fig. 4b). The results from IB analysis confirmed that $\mathrm{MCP}^{-1}{ }^{-1-}$ and $\mathrm{CCR} 2^{-1-}$ mice were less affected by ethanol-induced caspase 3 activation (Fig. $4 \mathrm{~b}$ ); $\mathrm{F}(2,33)=16.57, p \leq 0.05$ for the cortex, and $\mathrm{F}(2,33)=9.04, \quad p \leq 0.05$, for the cerebellum. It appeared that CCR2 deletion did not offer protection in the cerebellum. MCP-1 and CCR2 deficiency-mediated protection against ethanol-induced neurodegeneration was confirmed by a decrease in Fluoro-Jade C-positive cells in $\mathrm{MCP}-1^{-/-}$and $\mathrm{CCR} 2^{-/-}$mice, compared to WT mice following ethanol exposure (Fig. 4c).

\section{Bindarit and RS504393 alleviate ethanol-induced proinflammatory cytokines and microglial activation}

Ethanol-induced neuronal death is accompanied by neuroinflammation which may play a role in CNS damage. We sought to determine whether Bindarit or RS504393 can reduce ethanol-induced neuroinflammation. Interleukin-6 (IL-6) and tumor necrosis factor alpha (TNF $\alpha)$ are major pro-inflammatory cytokines that are involved in injuries in the CNS [46, 47]. Ethanol increased the expression of IL-6 and TNFa in the brain of PD4 mice and cultured SIM-A9 cells; Bindarit and RS504393 inhibited ethanol-induced increase of IL-6 $[\mathrm{F}(3,20)=40.12 ; p \leq 0.05]$, and TNF $\alpha \quad[\mathrm{F}(3,20)=31.21$; $p \leq 0.05]$ in the developing brain (Fig. 5a) and in cultured SIM-A9 cells [IL6, $\mathrm{F}(3,8)=29.31 ; \mathrm{p} \leq 0.05 ; \mathrm{TNF} \alpha, \mathrm{F}(3,8)$ $=30.54 ; p \leq 0.05$ ] (Fig. 5b). Pathological activation of microglia is involved in neuroinflammation and neurodegeneration in various CNS disorders [48-51]. We 

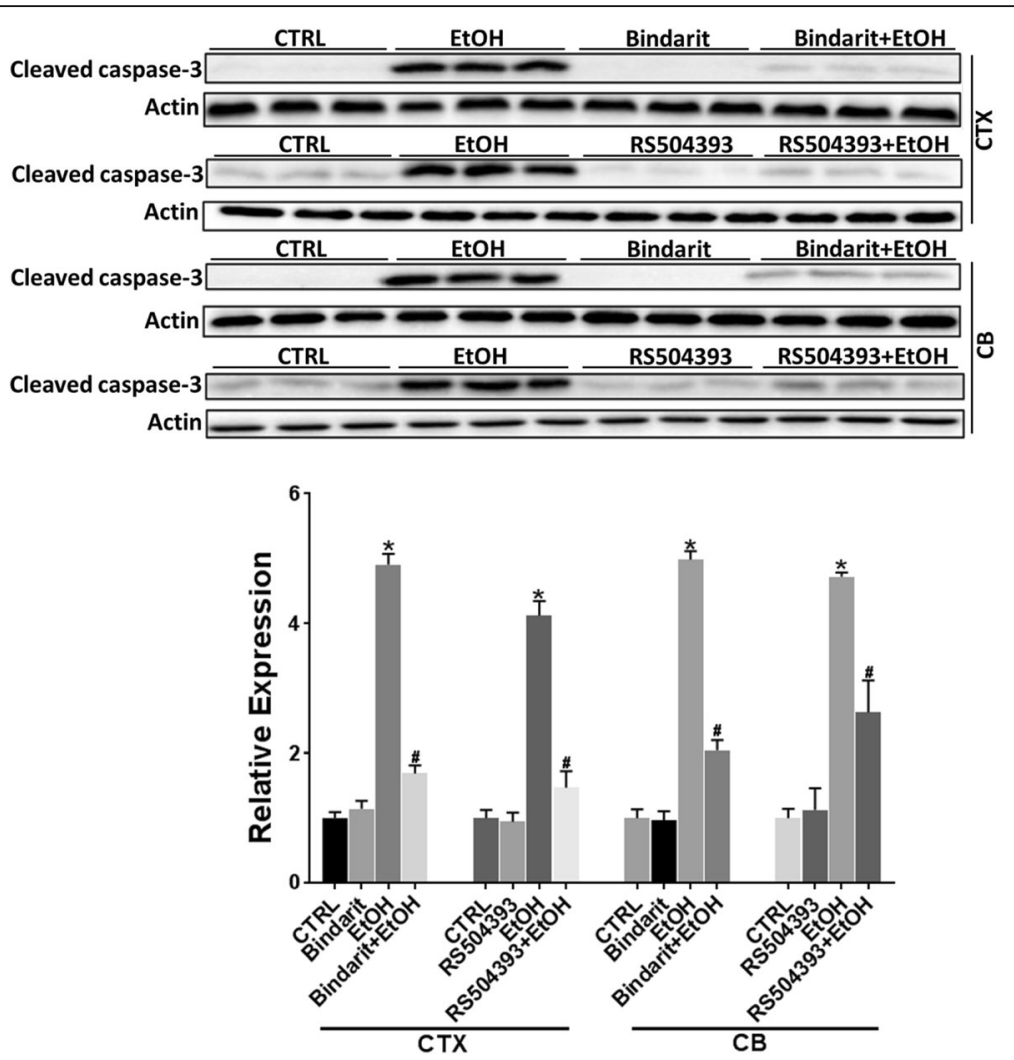

Fig. 3 Effect of Bindarit and RS504393 on ethanol-induced apoptotic neuronal death in the developing mouse brain. Bindarit (100 mg/kg) or RS504393 (1 mg/kg) was administered by two subcutaneous (SC) injections at 24 and $0.5 \mathrm{~h}$ prior to EtOH exposure as described in the "Methods" section. $8 \mathrm{~h}$ after EtOH injection, the pups were sacrificed and the brains were harvested. The expression of cleaved caspase- 3 in the cerebral cortex (CTX) and cerebellum (CB) was determined by IB and quantified by the normalization to actin. Each data point was the mean \pm SEM of six animals. ${ }^{*} p<0.05$, statistically significant difference from control group; \# $p<0.05$, statistically significant difference from EtOH-treated group

therefore examined the effect of Bindarit or RS504393 on ethanol-induced microglia activation. Microglial activation was assessed morphologically by IHC of Iba-1. Ethanol significantly increased the number of active microglia; Bindarit and RS504393 inhibited ethanol-induced activation of microglia $[F(5,12)=200.63 ; p \leq 0.05]$ (Fig. 6).

\section{Bindarit and RS504393 protect neurons against ethanol-} induced neuronal death in co-cultures of primary neurons and microglia cells

Since inhibition of MCP-1/CCR2 signaling alleviated ethanol-induced neuroapoptosis and microglial activation in the developing brain, we hypothesized that MCP-1/CCR2-regulated microglial activation may contribute to neuronal death. To test this hypothesis, we used a co-culture system in which primary neurons (mouse cortical neurons or cerebellar neurons) and microglial cells (SIM-A9 cells) were cultured together, allowing communication without direct contact. As shown in Fig. 7a, ethanol- and MCP-1-induced neuronal death was greater in microglia/neuron co-cultures than in cerebellar neuron cultures $[\mathrm{F}(6,14)=34.18, p \leq 0.05]$ or cortical neuron cultures $[\mathrm{F}(6,14)=32.45, p \leq 0.05]$ alone. Bindarit and RS504393 significantly ameliorated ethanol-induced neuronal death in the microglia/cerebellar neuron co-cultures $[\mathrm{F}(6,14)=28.71, p \leq 0.05]$, and microglia/cortical neuron co-cultures $[\mathrm{F}(6,14)=26.19$, $\mathrm{p} \leq 0.05$ ] (Fig. 7b).

\section{TLR4 and GSK3 $\beta$ mediate ethanol-induced} proinflammatory cytokines in microglial cells

It is well established that TLR4 and its downstream adaptors TRIF and MyD88 regulate microglial activation and production of inflammatory mediators [52-54]. GSK3 $\beta$ is also a key mediator of microglial activation and neuroinflammation [55-57]. MCP-1 was shown to activate GSK3 $\beta$ signaling in human breast carcinoma cells [58]. We hypothesized that the interaction among MCP-1/CCR2, TLR4, and GSK3 $\beta$ may mediate ethanol-induced microglial activation and expression of proinflammatory factors. We first determined whether TLR4 and GSK3 $\beta$ were involved in ethanol-induced expression of proinflammatory cytokines. We pre-treated SIM-A9 cells with either TLR4 inhibitor TAK242 or 


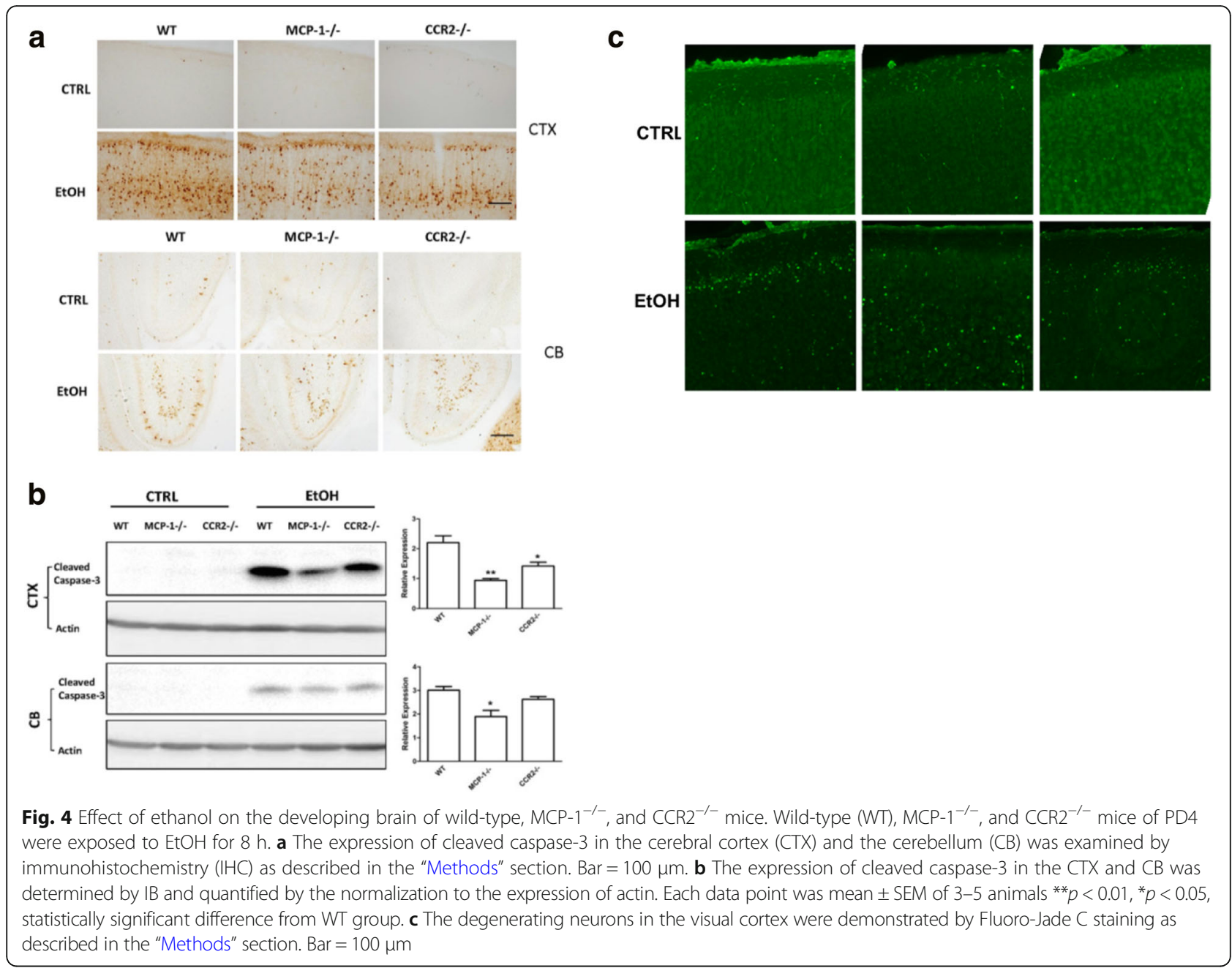

GSK3 $\beta$ inhibitor SB216763 to block TLR4 and GSK3 $\beta$ signaling prior to ethanol exposure. As shown in Fig. 8, TAK242 and SB216763 drastically attenuated ethanol-induced increase in the expression of Iba- $1[\mathrm{~F}(3,8)=40.13$, $p \leq 0.05]$, IL-6 $[\mathrm{F}(3,8)=56.78, \quad p \leq 0.05]$, and TNF- $\alpha$ $[\mathrm{F}(3,8)=65.17, p \leq 0.05]$. We next sought to determine whether MCP-1/CCR2 signaling was involved in ethanol-activated GSK3 $\beta$ and TLR4. The activity of GSK3 $\beta$ is mainly regulated by the phosphorylation at serine 9 which results in the inhibition of GSK3 $\beta$ [59-61], conversely, the phosphorylation at tyrosine 216 positively regulated its activity [62]. As shown in Fig. 9a, ethanol activated GSK3 $\beta$ by reducing the phosphorylation at Ser9 in SIM-A9 cells; blocking MCP-1/CCR2 signaling by Bindarit or RS504393 attenuated ethanol-induced dephosphorylation of GSK3 $\beta$ (Ser9) $[\mathrm{F}(3,8)=50.87, p \leq 0.05]$. Blocking MCP-1/CCR2 signaling also inhibited ethanolinduced TLR4 $(F(3,8)=35.27 ; p<0.05)$. Animal studies confirmed these findings and showed that Bindarit or RS504393 treatment attenuated ethanol-induced dephosphorylation of GSK3 $\beta$ (Ser9) $[\mathrm{F}(3,8)=59.54 ; p \leq 0.05]$ and upregulation of TLR4 $[\mathrm{F}(3,8)=52.18 ; p \leq 0.05]$, MyD88 $[\mathrm{F}(3,8)=57.15, \quad p \leq 0.05]$, and $\operatorname{TRIF}[\mathrm{F}(3,8)=63.17$; $p \leq 0.05]$ in the brain of PD4 mice (Fig. 9b).

We then investigated the interaction between TLR4 and GSK3 $\beta$ in response to ethanol exposure. Inhibition of TLR4 signaling by TAK242 attenuated ethanol-induced dephosphorylation of GSK3 $\beta$ (Ser9) $[F(3,8)=19.98$; $p \leq 0.05]$ and upregulation of MCP-1 $[\mathrm{F}(3,8)=56.78$; $p \leq 0.05$ ] in SIM-A9 cells (Fig. 9c). On the other hand, blocking GSK3 $\beta$ activation by SB216763 inhibited ethanol-induced increase of MCP-1 $[\mathrm{F}(3,8)=70.35$; $p \leq 0.05]$ and TLR4 $[\mathrm{F}(3,8)=42.36 ; p \leq 0.05]$ (Fig. 9d). The results indicated that there was considerable interaction among MCP-1/CCR2 signaling, TLR4, and GSK3 $\beta$ in response to ethanol exposure.

\section{Discussion}

In this study, we showed that ethanol increased the expression of MCP-1 but not CCR2 in the brain of PD4 mice and microglia cells (SIM-A9). MCP-1 synthesis inhibitor Bindarit and CCR2 antagonist RS504393 

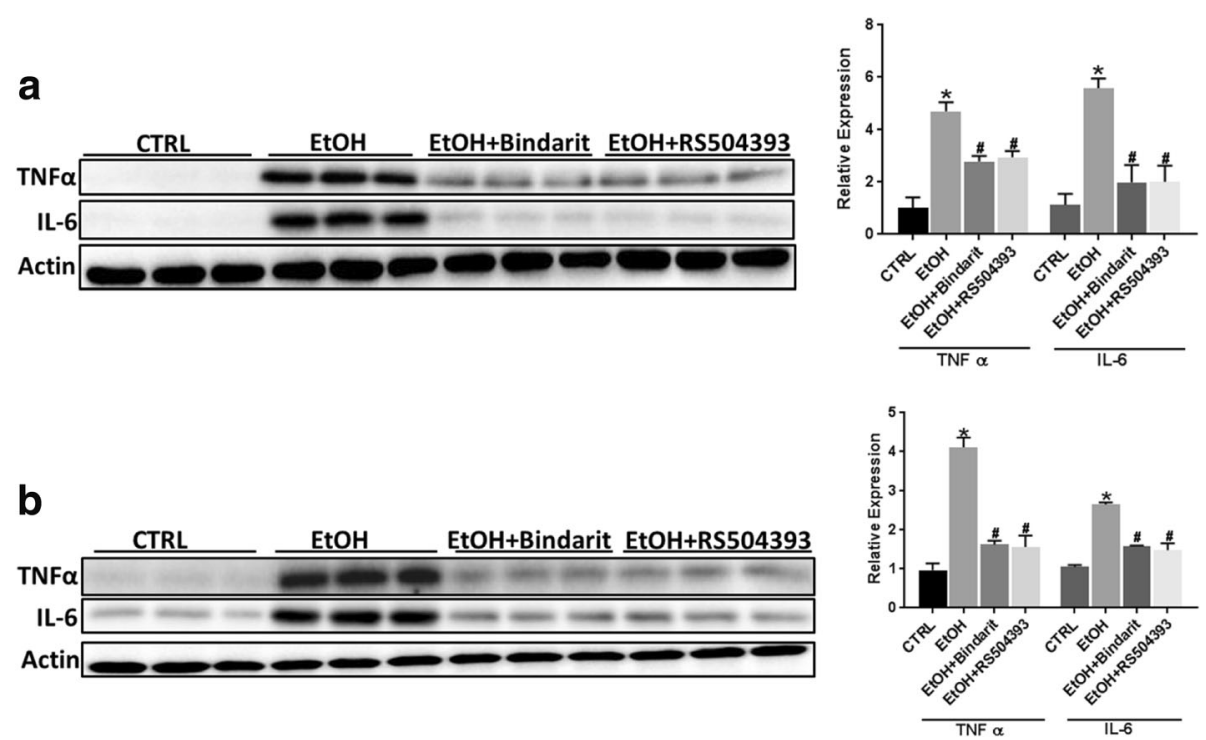

Fig. 5 Effect of Bindarit and RS504393 on ethanol-induced inflammation in the developing brain and SIM-A9 cells. a Bindarit (100 mg/kg) or RS504393 (1 mg/kg) was administered by two subcutaneous (SC) injections at 24 and 0.5 h prior to EtOH exposure as described in the "Methods" section. $8 \mathrm{~h}$ after EtOH injection, the pups were sacrificed and the brains were harvested. The relative expression for proinflammatory cytokines IL-6 and TNFa in the brain of PD4 mice were determined with IB and quantified as described above. Each data point was the mean \pm SEM of six animals. ${ }^{*} p \leq 0.05$, statistically significant difference from control group; ${ }^{\#} p \leq 0.05$, statistically significant difference from EtOH-treated group. $\mathbf{b}$ SIM-A9 cells were pretreated with Bindarit $(300 \mu \mathrm{M})$ or RS504393 $(100 \mu \mathrm{M})$ for $12 \mathrm{~h}$ prior to EtOH $(0.4 \%)$ exposure. After ethanol exposure for $12 \mathrm{~h}$, cells were harvested and processed for the expression of proinflammatory IL- 6 and TNFa by IB as described above. Data are the mean \pm SEM of three independent experiments. ${ }^{*} p<0.05$, statistically significant difference from control group; ${ }^{*} p<0.05$, statistically significant difference from EtOH-treated group

inhibited ethanol-induced neuroapoptosis, microglial activation, and the expression of pro-inflammatory factors. Further studies using gene knock out mice confirmed that the deficiency in MCP-1 or CCR2 made mice more resistant to ethanol-induced neurodegeneration.
Moreover, ethanol and MCP-1 caused more neuronal death in neuron/microglia co-cultures than neuronal culture alone. Blocking MCP-1/CCR2 signaling protected primary cortical and cerebellar neurons against ethanol-induced death in the neuron/microglia

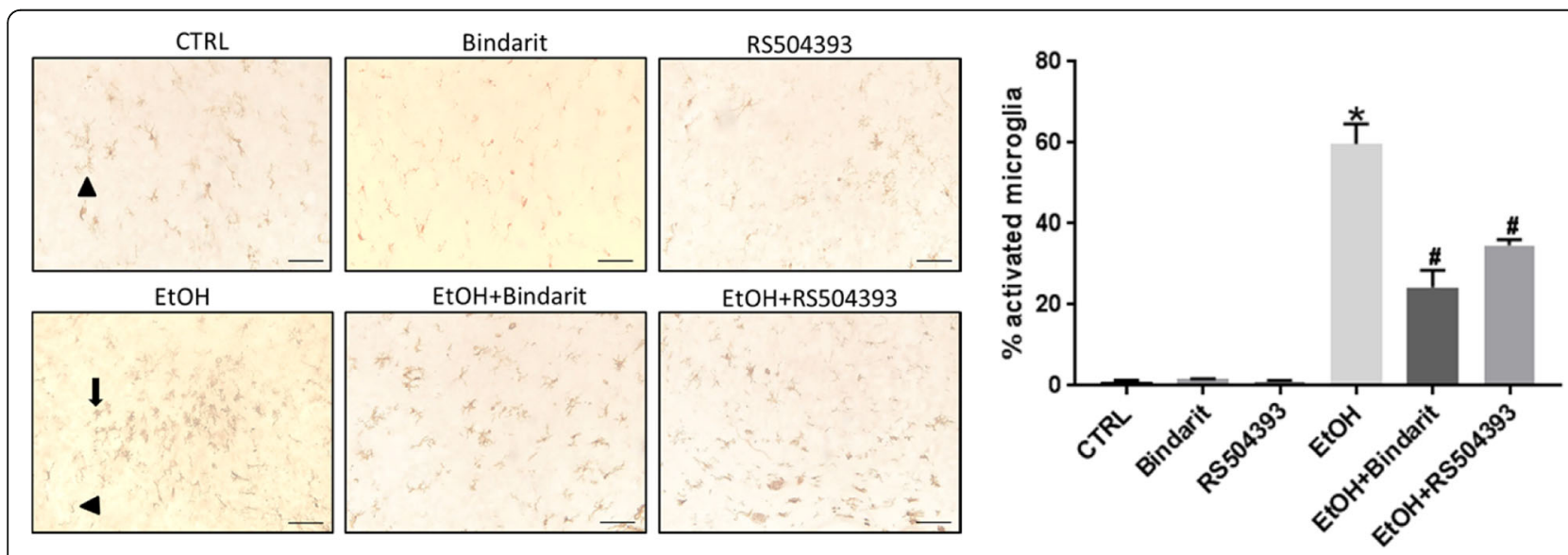

Fig. 6 Effect of Bindarit and RS504393 on ethanol-induced microglial activation in the developing mouse brain. Bindarit (100 mg/kg) or RS504393 (1 mg/kg) was administered by two subcutaneous (SC) injections at 24 and $0.5 \mathrm{~h}$ prior to EtOH exposure as described above. $8 \mathrm{~h}$ after EtOH injection, the pups were sacrificed and the brains were harvested. A representative image of inferior colliculus is shown. Microglia were identified by IHC of Iba-1. The resting microglia exhibit long branching processes and a small cellular body, which are indicated by arrow heads; while the activated microglia have fewer but thicker processes with a larger cell body, which are indicated by arrows. The percentage of activated Iba-1 positive cells in total Iba-1 positive cells was calculated as described in the "Methods" section. Bar $=50 \mu \mathrm{m}$. Each data point was the mean \pm SEM of three animals. ${ }^{*} p<0.05$, statistically significant difference from control group, ${ }^{*} p<0.05$, statistically significant difference from EtOH-treated group 

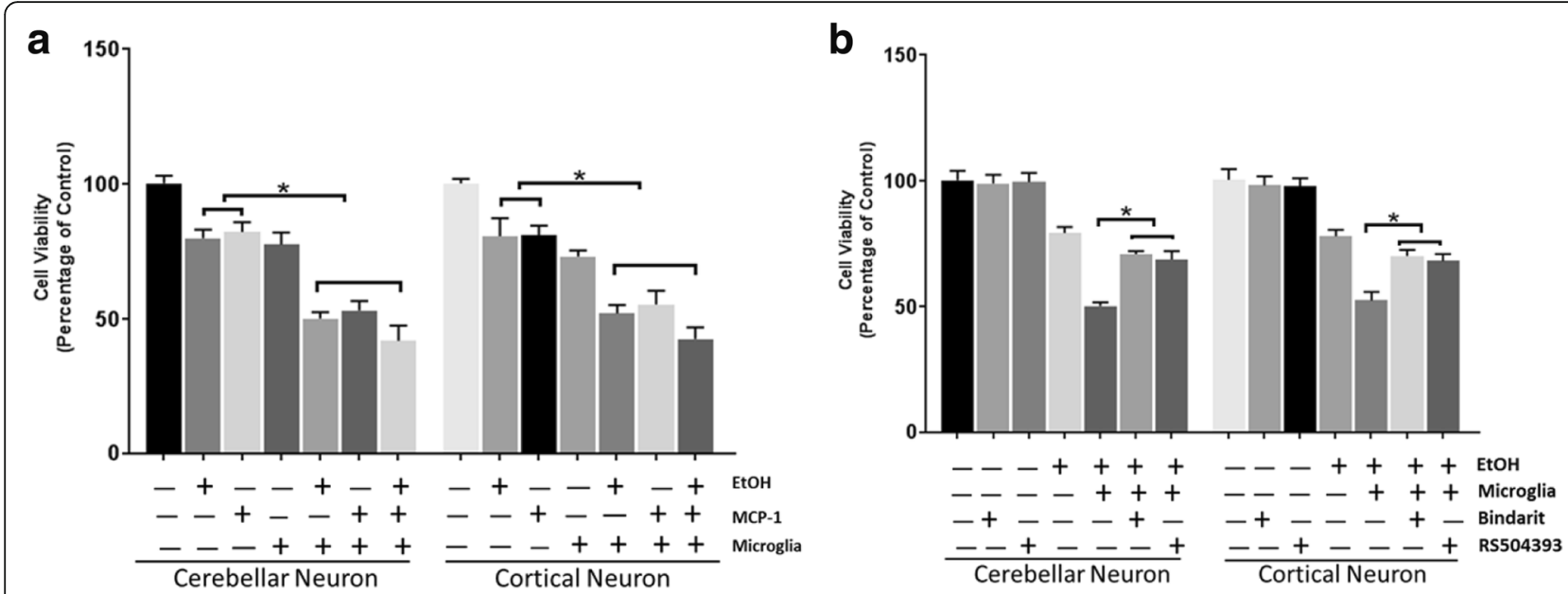

Fig. 7 Effect of Bindarit and RS504393 on ethanol-induced neuronal death in the co-cultures of microglia/primary neurons. a Co-cultures of SIM-A9 cells and primary cortical neurons/cerebellar neurons were established described in the "Methods" section. The co-cultures were treated with MCP-1 $(10 \mathrm{ng} / \mathrm{ml}$ in PBS) or EtOH (0.4\%) for $48 \mathrm{~h}$. The viability of neurons was determined by MTT as described in the "Methods" section. Data were the mean \pm SEM of three independent experiments. ${ }^{*} p<0.05$, statistically significant difference from primary neuronal culture alone. $\mathbf{b}$ SIM-A9 cells were treated with Bindarit $(300 \mu \mathrm{M})$ or RS504393 $(100 \mu \mathrm{M})$ for $12 \mathrm{~h}$. After that, the inserts containing SIM-A9 cells were placed in the culture wells containing cortical neurons or cerebellar neurons. The co-cultures were then treated with $\mathrm{EtOH}(0.4 \%)$ for $48 \mathrm{~h}$, and the viability of neurons was determined by MTT. Each data point was the mean \pm SEM of three independent experiments. ${ }^{*} p<0.05$, statistically significant difference from co-cultures without Bindarit or RS504393 treatment

co-cultures. It appeared that TLR4 and GSK3 $\beta$ mediated ethanol-induced microglial activation and pro-inflammatory cytokines in cultured microglia cells, and there was considerable interaction among TLR4, GSK3 $\beta$, and MCP-1/CCR2 signaling in response to ethanol exposure.

The mechanisms underlying ethanol-induced neurodegeneration in the developing brain are complex. Multiple mechanisms may be involved; these include oxidative stress [63, 64], endoplasmic reticulum (ER) stress [25], and interference of signaling by neurotrophic factors and disruption of microRNAs [65]. Recent evidence indicates that neuroinflammation plays an important role in the pathogenesis of FASD and AUD [12, 66, 67].
Ethanol-induced neurodegeneration in both adult and developing brain is accompanied by microglial activation and neuroinflammation $[12,66,68,69]$. We have recently shown that inhibition of microglial activation and neuroinflammation by minocycline offered protection against ethanol-induced neurodegeneration in the developing brain [41], suggesting that microglial activation and neuroinflammation may contribute to ethanol neurotoxicity in the immature CNS.

MCP-1 is a key chemokine involved in neuroinflammation. In mouse and human brain, MCP-1 and its receptor CCR2 are primarily expressed by microglia [8]. MCP-1/CCR2 signaling is involved in numerous

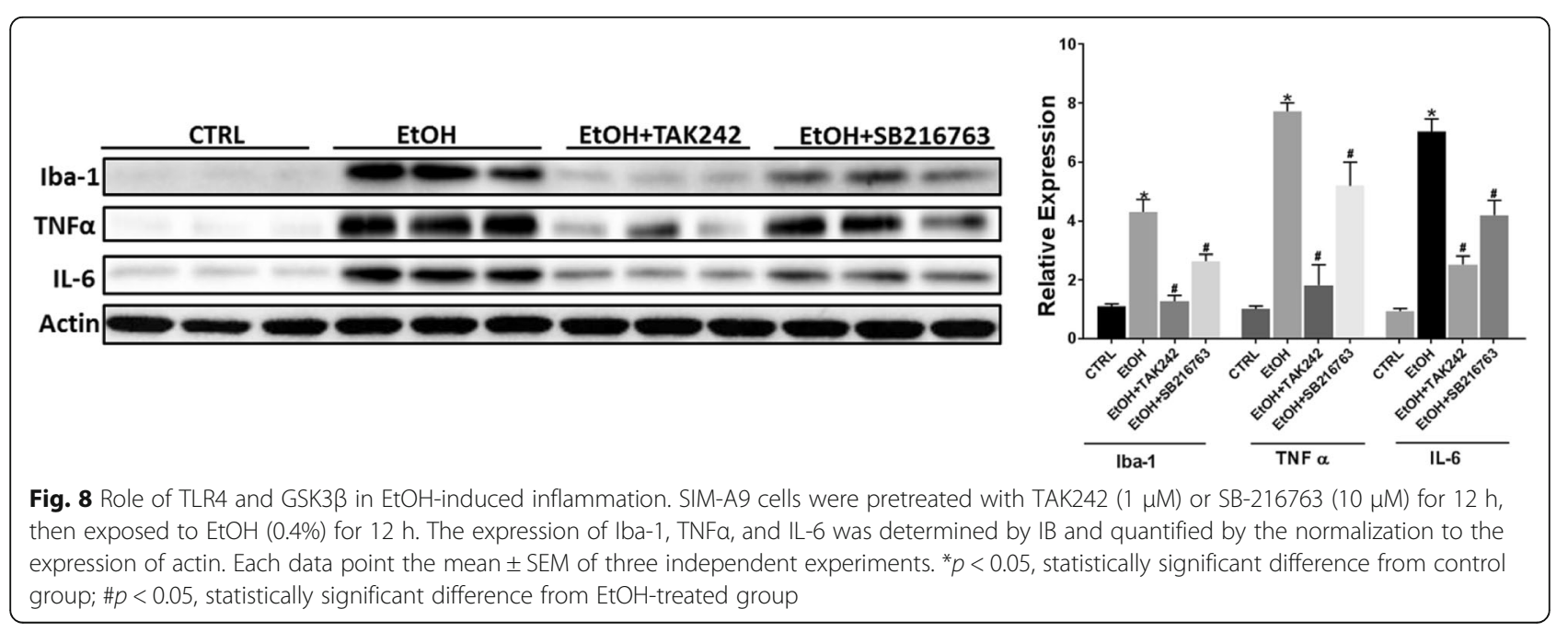




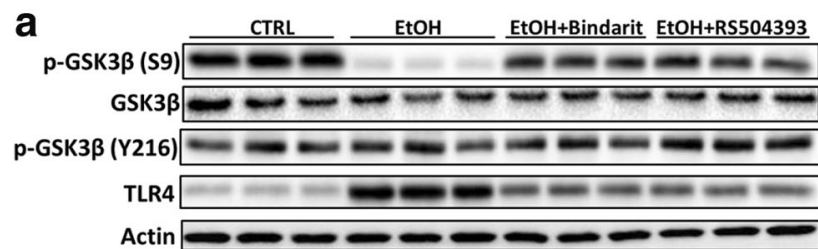

Actin $-\infty-\infty-\infty-\infty$
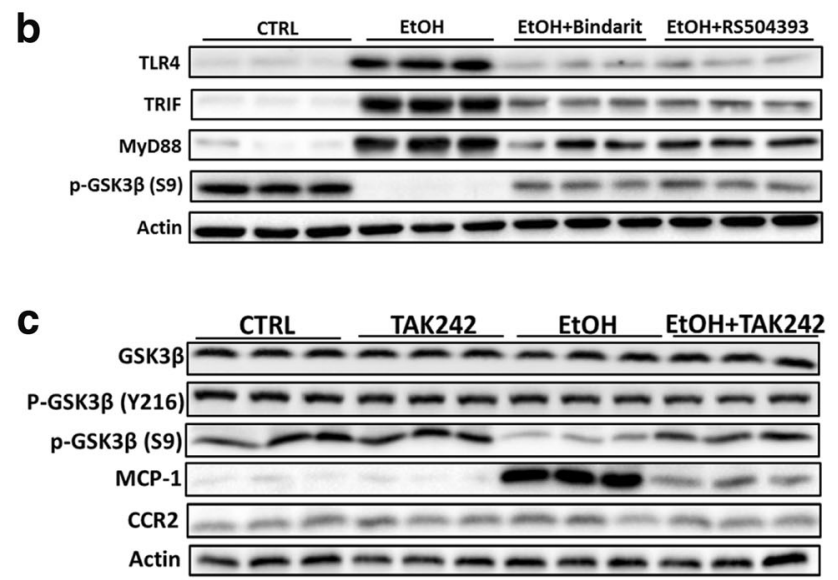

d

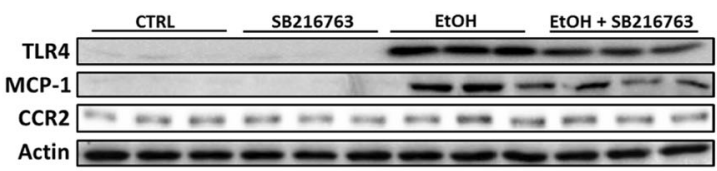

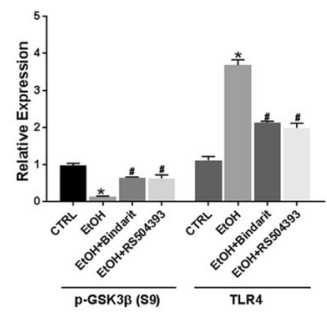
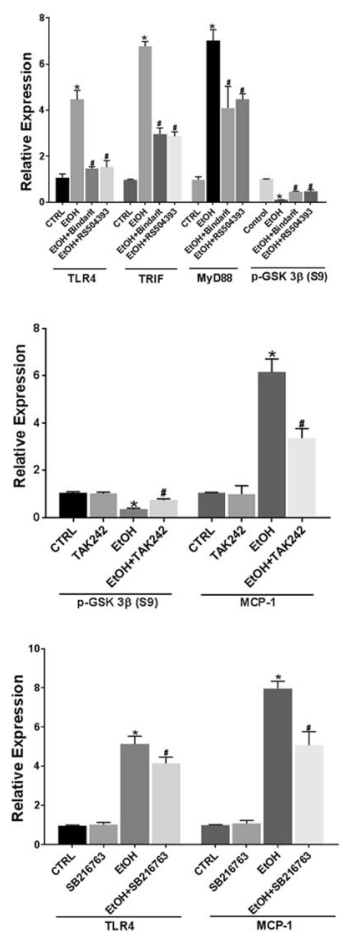

Fig. 9 The interaction of MCP-1/CCR2 signaling, TLR4 and GSK3ß in response to ethanol exposure. a SIM-A9 cells were pretreated with RS504393 $(100 \mu \mathrm{M})$ or Bindarit $(300 \mu \mathrm{M})$ for $12 \mathrm{~h}$, and then exposed to EtOH $(0.4 \%)$ for $12 \mathrm{~h}$. The expression of GSK3 $\beta$, phosphorylated GSK3 $\beta$ at serine 9 (phospho-GSK3 $\beta^{S 9}$ ), phosphorylated GSK3 $\beta$ at tyrosine 216 (phospho-GSK3 ${ }^{\text {Y216 }}$ ), and TLR4 were determined by IB and quantified by the normalization to the expression of actin. $\mathbf{b}$ C57BL6 mice of PD4 were treated with Bindarit, RS504393, and EtOH as described in Fig. 2. $8 \mathrm{~h}$ after EtOH treatment, the expression of TLR4 and its downstream adaptors TRIF and MyD88, and phospho-GSK3 $\beta^{S 9}$ in the brain was determined by IB and quantified by the normalization to the expression of actin. c SIM-A9 cells were pretreated with TAK242 (1 $\mu \mathrm{M})$ for $12 \mathrm{~h}$, and then exposed to EtOH (0.4\%) for $12 \mathrm{~h}$. The expression of GSK33, phospho-GSK3 $\beta^{S 9}$, phospho-GSK3 $\beta^{\mathrm{Y} 216}, \mathrm{MCP}-1$, and CCR2 was by IB and quantified by the normalization to the expression of actin. d SIM-A9 cells were pretreated SB-216763 $(10 \mu \mathrm{M})$ for $12 \mathrm{~h}$, and then exposed to EtOH (0.4\%) for $12 \mathrm{~h}$. The expression of TLR4, MCP-1, and CCR2 was by IB and quantified by the normalization to the expression of actin. Each data point was the mean $\pm \mathrm{SEM}$ of three independent experiments. ${ }^{*} p<0.05$, statistically significant difference from control group; $\# p<0.05$, statistically significant difference from EtOH-treated group

neuroinflammatory diseases, such as multiple sclerosis, stroke, and Alzheimer's disease [14-19]. Chronic ethanol exposure induces MCP-1 expression in adult human and mice brain $[24,25]$. We have recently shown that ethanol stimulated MCP-1/CCR-2 signaling in the spinal cord of early postnatal mice, and knocking out MCP-1 or CCR2 made mice resistant to ethanol-induced apoptosis of spinal cord neurons [70], indicating the involvement of MCP-1/CCR2 signaling in ethanol-induced neurodegeneration in the developing spinal cord.

The current study showed that ethanol upregulated MCP-1 at both mRNA and protein levels but not CCR2 expression in the developing brain. Ethanol stimulation of MCP-1/CCR2 signaling was confirmed by an upregulation of the downstream effector, MCPIP (Fig. 2). Disrupting MCP-1/CCR2 signaling by either MCP-1 synthesis inhibitor or CCR2 antagonist made mice less susceptible to ethanol-induced apoptotic cell death, microglial activation, and the expression of pro-inflammatory factors (Figs. 3, 4, 5, and 6). Gene deletion of MCP-1 or CCR2 also offered protection against ethanol-induced neurodegeneration in the developing brain (Fig. 4). It appears that MCP-1 deletion provided better protection than CCR2 deletion (Fig. 4b). The underlying mechanisms are currently unknown. It is possible that MCP-1 may interact with other chemokine receptors than CCR2 in microglia. It is reported 
that MCP-1 binds to CCR5 in osteoblastic cells [71]. MCP-1/CCR2 signaling plays an important role in microglial activation and neuroinflammation [8-10, 72]. Therefore, the neuroprotection caused by the disruption of MCP-1/CCR2 signaling may result from suppression of microglial activation and neuroinflammation. Using a neuron/microglia co-culture system, we demonstrated that the presence of microglial cells indeed exacerbated ethanol-induced neuronal death; while blocking MCP-1/ CCR2 signaling attenuated enhanced ethanol neurotoxicity in this neuron/microglia co-culture system (Fig. 7). The result further supported the hypothesis that the activation of microglia contributed to ethanol neurotoxicity. Although our findings suggest that MCP-1/CCR2-mediated microglial activation and neuroinflammation is involved in ethanol neurotoxicity, we could not rule out the possibility of ethanol directly killing the neurons. In primary neuronal cultures alone, ethanol also reduced neuronal viability but to a lesser extent, compared to neuron/microglia co-cultures (Fig. 7). It is possible that in the brain, ethanol initially causes neuronal damage, triggering MCP-1/ CCR2-mediated microglial activation and neuroinflammation, which further exacerbates neurodegeneration.

Although MCP-1 and CCR2 are primarily expressed by microglia in mouse and human brain, they are also expressed in other cell types in the brain, such as astrocytes and neurons, but to a lesser extent $[8,73,74]$. Therefore, the situation in vivo is complex and it is difficult to separate the effects of microglia-derived MCP-1 from that deprived from other cell types unless microglia-specific MCP-1 or CCR2 knock out mice are available.

TLR4, GSK3 $\beta$, and p38 MAPK are important regulators of microglial activation and neuroinflammation [44, $52,54,75,76]$. Since ethanol had little effect on p38 MAPK in the developing brain [41], we focused on TLR4 and GSK3 $\beta$ in this study. Indeed, TLR4 and GSK3 $\beta$ were activated by ethanol and involved in ethanol-induced microglial activation and upregulation of proinflammatory cytokines (Figs. 8 and 9). Ethanol activated GSK3 $\beta$ by inducing dephosphorylation of GSK3 $\beta$ at Ser9 in vitro and in vivo (Fig. 9a, b). This is consistent with our previous findings that ethanol decreased the phosphorylation of GSK3 $\beta$ (Ser9) in the developing brain and cultured neuronal cells [60, 77]. Blocking MCP-1/ CCR2 signaling partially mitigated ethanol-induced dephosphorylation of GSK3 $\beta$ (Ser9), therefore alleviating ethanol-mediated activation of GSK3 $\beta$. Similarly, blocking MCP-1/CCR2 signaling effectively inhibited ethanolinduced upregulation of TLR4 in vitro and in vivo (Fig. 9a, b). These results suggest that MCP-1/CCR2 signaling was involved in ethanol-induced activation of GSK3 $\beta$ and TLR4.

It appears that there was considerable interaction among MCP-1/CCR2 signaling, GSK3 $\beta$, and TLR4 in response to ethanol exposure. Blocking TLR4 by TAK242 alleviated ethanol-induced dephosphorylation of GSK3 $\beta$ (Ser9) and partially inhibited ethanol-induced upregulation of MCP-1 (Fig. 9c). On the other hand, blocking GSK3 $\beta$ also attenuated ethanol-induced upregulation of MCP-1 and TLR4 (Fig. 9d). Based on these findings, we propose a model to illustrate the cascade of ethanol-induced microglial activation and neuroinflammation (Fig. 10). In this model, ethanol could directly or indirectly activate TLR4 and stimulate its downstream effectors such as TRIF and MyD88; the active TLR4 may also activate GSK3 $\beta$ which may further stimulate TLR4. As a result, the activation of TRIF, MyD88, and GSK3 $\beta$ stimulates transcription factors, such as AP-1 and $\mathrm{NF}-\kappa \mathrm{B}$ which upregulate the expression of proinflammatory cytokines and chemokines (e.g., TNF- $\alpha$, IL6, and MCP-1). The released MCP-1 interacts with CCR2 and further activates GSK3 $\beta$ and TLR4; the positive feedback loop intensifies the neuroinflammation toxic to neurons. It is also possible that ethanol could directly activate CCR2 and initiate the downstream signaling cascades. This possibility is worthy of further investigation.

There are several important implications from this study. The current finding establishes an important role of GSK3 $\beta$ in microglial activation and neuroinflammation. We have previously demonstrated that ethanol-induced activation of GSK3 $\beta$ in neurons may cause neurodegeneration in the developing brain and in vitro [78]. Our recent study showed that minocycline inhibited GSK3 $\beta$ and offered protection against ethanol neurotoxicity in the developing brain [41]. Together, these findings suggest that the activation of GSK3 $\beta$ in both neurons and microglia contributes to ethanol neurotoxicity, although it may operate by different mechanisms. It further supports that both neuronal and microglial GSK3 $\beta$ are valid therapeutic targets for the treatment of ethanol neurotoxicity in the developing CNS.

In addition to the microglial activation and neuroinflammation, stimulation of MCP-1/CCR2 signaling may cause neurotoxicity through other mechanisms. For example, the activation of MCP-1/CCR2 signaling is reported to cause ER stress through the upregulation of MCPIP in cardiomyocytes and osteoclasts [79]. Kim et al. showed that CCR2 inhibitor attenuated ER stress and decreased the expression of inflammatory cytokines in the liver of type 2 diabetic mice [80]. ER stress has recently been proposed as an important mechanism for ethanol-induced damage to the CNS [25, 81]. Ethanol-induced ER stress in the developing spinal cord is significantly reduced in $\mathrm{MCP}-1^{-/-}$and $\mathrm{CCR} 2^{-/-}$mice [70]. Therefore, it is also likely that ethanol-induced upregulation of MCP-1 may cause ER stress which exacerbates neurodegeneration in the developing CNS. 


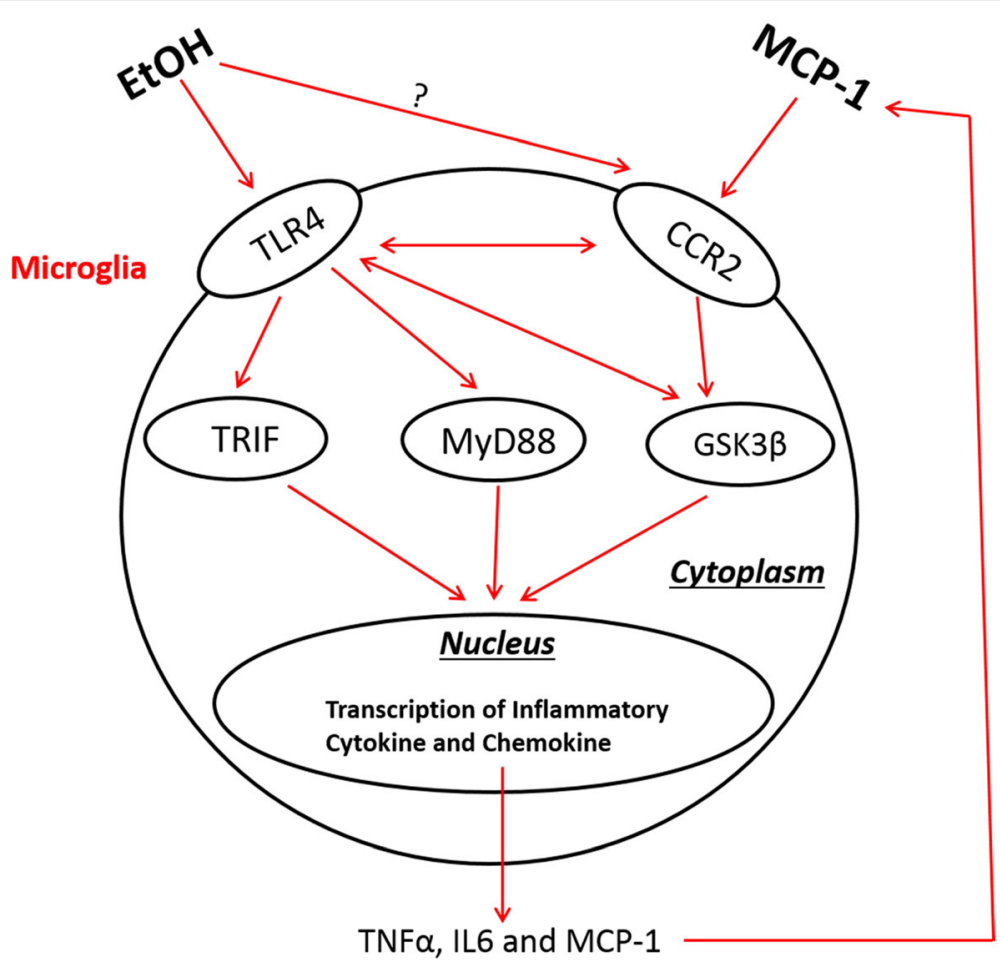

Fig. 10 The interaction among MCP-1/CCR2 signaling, TLR4, and GSK3 3 in ethanol-induced neuroinflammation. EtOH may stimulate TLR4 and possibly CCR2, and activate the downstream effectors, such as TRIF and MyD88. Active TLR4 may also activate GSK3 $\beta$ which may further stimulate TLR4 pathway. As a result, the activation of TRIF, MyD88, and GSK3 $\beta$ stimulates transcription factors which upregulate the expression of proinflammatory cytokines and chemokines (e.g., TNF-a, IL6, and MCP-1). The released MCP-1 interacts with CCR2 and further activates TLR4 and GSK33; the positive feedback loop intensifies the neuroinflammation that is toxic to neurons in the developing CNS

MCP-1/CCR2 signaling has been implicated in AUD. For example, it is shown that MCP-1/CCR2 signaling regulates voluntary ethanol consumption. MCP-1 is also involved in ethanol-induced anxiety-like behavior in adolescent rats [82]. The current finding along with our recent study [70] add that MCP-1/CCR2-mediated neuroinflammation and microglial activation contribute to ethanol neurotoxicity in the developing CNS. Thus, MCP-1/CCR2 signaling is likely also involved neurological deficits in associated with FASD.

\section{Conclusion}

In conclusion, $\mathrm{MCP}-1 / \mathrm{CCR} 2$ signaling played an important role in ethanol-induced microglial activation/neuroinflammation and neurodegeneration in the developing brain. The findings offer a potential new therapeutic avenue for FASD by targeting MCP-1/CCR2 signaling pathway.

\section{Abbreviation}

AD: Alzheimer's disease; AUD: Alcohol use disorders; CCR2: Chemokine ( $C-C$ motif) receptor 2; CNS: Central nervous system; ER: Endoplasmic reticulum; FASD: Fetal alcohol spectrum disorder; GSK3ß: Glycogen synthase kinase 3 beta; Iba-1: lonized

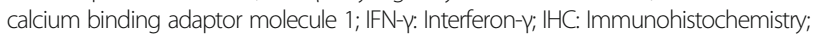
IL: Interleukin; MCP-1: Monocyte chemoattractant protein-1; PD: Parkinson's disease; TLR4: Toll-like receptor 4; TNF-a: Tumor necrosis factor-a

\section{Funding}

This research is supported by grants from the National Institutes of Health (NIH) (AA017226 and AA015407). It is also supported in part by the Department of Veterans Affairs, Veterans Health Administration, Office of Research and Development [Biomedical Laboratory Research and Development: Merit Review (BX001721)].

\section{Availability of data and materials}

The authors agree to share all data generated from this study.

\section{Authors' contributions}

KZ performed most experiments in vitro and in vivo, and analyzed/compiled the data. HW and MX performed $\mathrm{PPCR}, \mathrm{IHC}$, and IB analyses in MCP-1 ${ }^{-/-}$and $\mathrm{CCR}^{-/-}$mice. $\mathrm{KZ}$ and $\mathrm{JL}$ contributed to the experimental design and writing of the manuscript. JAF contributed to writing and editing the manuscript. All authors read and approved the final manuscript.

\section{Ethics approval}

All procedures were performed according to the Institutional Animal Care and Use Committee (protocol \#: 2008-0401).

Consent for publication

Not applicable

\section{Competing interests}

The authors declare that they have no competing interests.

\section{Publisher's Note}

Springer Nature remains neutral with regard to jurisdictional claims in published maps and institutional affiliations. 


\section{Received: 28 February 2018 Accepted: 26 June 2018}

\section{Published online: 05 July 2018}

\section{References}

1. May PA, et al. Prevalence and characteristics of fetal alcohol spectrum disorders. Pediatrics. 2014;134(5):855-66

2. Alimov A, et al. Expression of autophagy and UPR genes in the developing brain during ethanol-sensitive and resistant periods. Metab Brain Dis. 2013; 28(4):667-76.

3. Muralidharan $\mathrm{P}$, et al. Fetal alcohol spectrum disorder (FASD) associated neural defects: complex mechanisms and potential therapeutic targets. Brain Sci. 2013;3(2):964-91.

4. Drew PD, Kane CJ. Fetal alcohol spectrum disorders and neuroimmune changes. Int Rev Neurobiol. 2014;118:41-80.

5. Kane CJ, Phelan KD, Drew PD. Neuroimmune mechanisms in fetal alcohol spectrum disorder. Dev Neurobiol. 2012;72(10):1302-16.

6. Blanco AM, et al. Ethanol-induced iNOS and COX-2 expression in cultured astrocytes via NF-kappa B. Neuroreport. 2004;15(4):681-5.

7. Crews FT, et al. Cytokines and alcohol. Alcohol Clin Exp Res. 2006;30(4):720-30.

8. Conductier $\mathrm{G}$, et al. The role of monocyte chemoattractant protein MCP1/CCL2 in neuroinflammatory diseases. J Neuroimmunol. 2010;224(1-2):93-100.

9. $\mathrm{Xu} \mathrm{LL}$, et al. Human recombinant monocyte chemotactic protein and other C-C chemokines bind and induce directional migration of dendritic cells in vitro. J Leukoc Biol. 1996;60(3):365-71.

10. Carr MW, et al. Monocyte chemoattractant protein 1 acts as a T-lymphocyte chemoattractant. Proc Natl Acad Sci U S A. 1994:91(9):3652-6.

11. He J, Crews FT. Increased MCP-1 and microglia in various regions of the human alcoholic brain. Exp Neurol. 2008;210(2):349-58.

12. Chastain LG, Sarkar DK. Role of microglia in regulation of ethanol neurotoxic action. Int Rev Neurobiol. 2014;118:81-103.

13. Zhang $X$, et al. Prenatal alcohol exposure alters the course and severity of adjuvant-induced arthritis in female rats. Brain Behav Immun. 2012;26(3):439-50.

14. MCManus C, et al. MCP-1, MCP-2 and MCP-3 expression in multiple sclerosis lesions: an immunohistochemical and in situ hybridization study. J Neuroimmunol. 1998:86(1):20-9.

15. Simpson JE, et al. Expression of monocyte chemoattractant protein-1 and other beta-chemokines by resident glia and inflammatory cells in multiple sclerosis lesions. J Neuroimmunol. 1998;84(2):238-49.

16. Wang X, Feuerstein GZ. Induced expression of adhesion molecules following focal brain ischemia. J Neurotrauma. 1995;12(5):825-32.

17. Che $X$, et al. Monocyte chemoattractant protein-1 expressed in neurons and astrocytes during focal ischemia in mice. Brain Res. 2001;902(2):171-7.

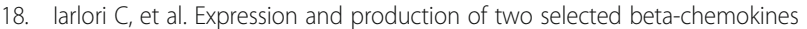
in peripheral blood mononuclear cells from patients with Alzheimer's disease. Exp Gerontol. 2005;40(7):605-11.

19. Reale $M$, et al. The acetylcholinesterase inhibitor, donepezil, regulates a Th2 bias in Alzheimer's disease patients. Neuropharmacology. 2006:50(5):606-13.

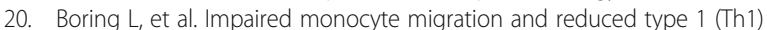
cytokine responses in C-C chemokine receptor 2 knockout mice. J Clin Invest. 1997:100(10):2552-61.

21. Kurihara $T$, et al. Defects in macrophage recruitment and host defense in mice lacking the CCR2 chemokine receptor. J Exp Med. 1997:186(10):1757-62.

22. Boring $L$, et al. Decreased lesion formation in CCR2-/- mice reveals a role for chemokines in the initiation of atherosclerosis. Nature. 1998;394(6696):894-7.

23. Huang D, et al. Chronic expression of monocyte chemoattractant protein-1 in the central nervous system causes delayed encephalopathy and impaired microglial function in mice. FASEB J. 2005;19(7):761-72.

24. Olney JW, et al. Ethanol-induced apoptotic neurodegeneration in the developing C57BL/6 mouse brain. Brain Res Dev Brain Res. 2002;133(2):115-26.

25. Ke Z, et al. Ethanol induces endoplasmic reticulum stress in the developing brain. Alcohol Clin Exp Res. 2011;35(9):1574-83.

26. Urso T, Gavaler JS, Van Thiel DH. Blood ethanol levels in sober alcohol users seen in an emergency room. Life Sci. 1981;28(9):1053-6.

27. Jones AW. The drunkest drinking driver in Sweden: blood alcohol concentration 0.545\% w/v. J Stud Alcohol. 1999:60(3):400-6.

28. van Hoof JJ, et al. Adolescent alcohol intoxication in the Dutch hospital departments of pediatrics: a 2-year comparison study. J Adolesc Health. 2011;48(2):212-4.

29. Jones AW, Harding P. Driving under the influence with blood alcoho concentrations over 0.4 g\%. Forensic Sci Int. 2013;231(1-3):349-53.
30. Malejko K, Graf H, Gahr M. Survival of very high blood alcohol concentration without consequential damage in a patient without a previous substance use disorder. J Forensic Sci. 2016;61(4):1155-7.

31. Wakida $\mathrm{N}$, et al. CC-chemokine ligand 2 facilitates conditioned place preference to methamphetamine through the activation of dopamine systems. J Pharmacol Sci. 2014;125(1):68-73.

32. Zollo M, et al. Targeting monocyte chemotactic protein-1 synthesis with bindarit induces tumor regression in prostate and breast cancer animal models. Clin Exp Metastasis. 2012;29(6):585-601.

33. Nagamoto-Combs K, Kulas J, Combs CK. A novel cell line from spontaneously immortalized murine microglia. J Neurosci Methods. 2014; 233:187-98.

34. Luo J, Miller MW. Differential sensitivity of human neuroblastoma cell lines to ethanol: correlations with their proliferative responses to mitogenic growth factors and expression of growth factor receptors. Alcohol Clin Exp Res. 1997;21(7):1186-94.

35. Paccosi $\mathrm{S}$, et al. The chemokine ( $\mathrm{C}-\mathrm{C}$ motif) ligand protein synthesis inhibitor bindarit prevents cytoskeletal rearrangement and contraction of human mesangial cells. Cytokine. 2016:85:92-100.

36. Mirzadegan $T$, et al. Identification of the binding site for a novel class of CCR2b chemokine receptor antagonists binding to a common chemokine receptor motif within the helical bundle. J Biol Chem. 2000;275(33):25562-71.

37. Ho DH, Ring AL, Pollock JS. Early-life stress induces increased plasma Heme and toll-like receptor 4 activation leading to increased superoxide production in aortic endothelial cells. FASEB J. 2016;30(1 Supplement):1214.2.

38. Lin S-Y, et al. GSK3-TIP60-ULK1 signaling pathway links growth factor deprivation to autophagy. Science. 2012;336(6080):477-81.

39. Chen $X$, et al. Expression and localization of inter-alpha inhibitors in rodent brain. Neuroscience. 2016;324:69-81.

40. Wang $X$, et al. Activation of double-stranded RNA-activated protein kinase by mild impairment of oxidative metabolism in neurons. J Neurochem. 2007:103(6):2380-90.

41. Wang $X$, et al. Minocycline protects developing brain against ethanolinduced damage. Neuropharmacology. 2018;129:84-99.

42. Wang $\mathrm{H}$, et al. Tunicamycin-induced unfolded protein response in the developing mouse brain. Toxicol Appl Pharmacol. 2015;283(3):157-67.

43. Chen $Z$, et al. Lipopolysaccharide-induced microglial activation and neuroprotection against experimental brain injury is independent of hematogenous TLR4. J Neurosci. 2012;32(34):11706-15.

44. Wang $\mathrm{M}-\mathrm{J}$, et al. Glycogen synthase kinase-3ß inactivation inhibits tumor necrosis factor-a production in microglia by modulating nuclear factor $\mathrm{KB}$ and MLK3/JNK signaling cascades. J Neuroinflammation. 2010;7(1):99.

45. Qin L, et al. Increased systemic and brain cytokine production and neuroinflammation by endotoxin following ethanol treatment. J Neuroinflammation. 2008:5:10

46. Vallieres L, Rivest S. Interleukin-6 is a needed proinflammatory cytokine in the prolonged neural activity and transcriptional activation of corticotropinreleasing factor during endotoxemia. Endocrinology. 1999;140(9):3890-903.

47. Wang WY, et al. Role of pro-inflammatory cytokines released from microglia in Alzheimer's disease. Ann Transl Med. 2015;3(10):136.

48. Dheen ST, Kaur C, Ling EA. Microglial activation and its implications in the brain diseases. Curr Med Chem. 2007;14(11):1189-97.

49. Kaur G, et al. Microglia and central nervous system immunity. Neurosurg Clin N Am. 2010;21(1):43-51.

50. Lucin KM, Wyss-Coray T. Immune activation in brain aging and neurodegeneration: too much or too little? Neuron. 2009;64(1):110-22.

51. Lynch MA. The multifaceted profile of activated microglia. Mol Neurobiol. 2009;40(2):139-56.

52. Yao $\mathrm{L}$, et al. Toll-like receptor 4 mediates microglial activation and production of inflammatory mediators in neonatal rat brain following hypoxia: role of TLR4 in hypoxic microglia. J Neuroinflammation. 2013;10:23.

53. Facci $L$, et al. Toll-like receptors $2,-3$ and -4 prime microglia but not astrocytes across central nervous system regions for ATP-dependent interleukin-1 beta release. Sci Rep. 2014;4:6824

54. Fernandez-Lizarbe S, Pascual M, Guerri C. Critical role of TLR4 response in the activation of microglia induced by ethanol. J Immunol. 2009:183(7):4733-44.

55. Yuskaitis CJ, Jope RS. Glycogen synthase kinase-3 regulates microglial migration, inflammation, and inflammation-induced neurotoxicity. Cell Signal. 2009;21(2):264-73.

56. Llorens-Martin $M$, et al. Peripherally triggered and GSK-3beta-driven brain inflammation differentially skew adult hippocampal neurogenesis, 
behavioral pattern separation and microglial activation in response to ibuprofen. Transl Psychiatry. 2014;4:e463.

57. Cortes-Vieyra R, et al. Role of glycogen synthase kinase-3 beta in the inflammatory response caused by bacterial pathogens. J Inflamm (Lond). 2012;9(1):23.

58. Li S, et al. MCP-1-induced ERK/GSK-3beta/snail signaling facilitates the epithelial-mesenchymal transition and promotes the migration of MCF-7 human breast carcinoma cells. Cell Mol Immunol. 2016;14:621-30.

59. Golpich $M$, et al. Glycogen synthase kinase-3 beta (GSK-3beta) signaling: implications for Parkinson's disease. Pharmacol Res. 2015;97:16-26.

60. Luo J. GSK3beta in ethanol neurotoxicity. Mol Neurobiol. 2009;40(2):108-21.

61. Maixner DW, Weng HR. The role of glycogen synthase kinase 3 beta in neuroinflammation and pain. J Pharm Pharmacol (Los Angel). 2013;1 (1):001.

62. Medina M, Wandosell F. Deconstructing GSK-3: the fine regulation of its activity. Int J Alzheimers Dis. 2011;2011:479249.

63. Goodlett CR, Horn KH, Zhou FC. Alcohol teratogenesis: mechanisms of damage and strategies for intervention. Exp Biol Med (Maywood). 2005; 230(6):394-406.

64. Chen G, Luo J. Anthocyanins: are they beneficial in treating ethanol neurotoxicity? Neurotox Res. 2010;17(1):91-101.

65. Boyadjieva NI, Sarkar DK. Cyclic adenosine monophosphate and brainderived neurotrophic factor decreased oxidative stress and apoptosis in developing hypothalamic neuronal cells: role of microglia. Alcohol Clin Exp Res. 2013;37(8):1370-9.

66. Kane CJ, Drew PD. Inflammatory responses to alcohol in the CNS: nuclear receptors as potential therapeutics for alcohol-induced neuropathologies. J Leukoc Biol. 2016;100(5):951-9.

67. Crews FT, et al. The role of neuroimmune signaling in alcoholism. Neuropharmacology. 2017;122:56-73.

68. Saito $M$, et al. Ethanol-induced neurodegeneration and glial activation in the developing brain. Brain Sci. 2016;6(3) https://doi.org/10.3390/ brainsci6030031.

69. Wilhelm CJ, Guizzetti M. Fetal alcohol spectrum disorders: an overview from the glia perspective. Front Integr Neurosci. 2015;9:65.

70. Ren Z, et al. Ethanol-induced damage to the developing spinal cord: the involvement of CCR2 signaling. Biochim Biophys Acta. 2017;1863(11):2746-61.

71. Craig MJ, Loberg RD. CCL2 (monocyte chemoattractant protein-1) in cancer bone metastases. Cancer Metastasis Rev. 2006;25(4):611-9.

72. Selenica M-LB, et al. Diverse activation of microglia by chemokine (CC motif) ligand 2 overexpression in brain. J Neuroinflammation. 2013;10(1):856.

73. Stowe AM, et al. CCL2 upregulation triggers hypoxic preconditioninginduced protection from stroke. J Neuroinflammation. 2012;9(1):33.

74. Howe $\mathrm{CL}$, et al. Neuronal CCL2 expression drives inflammatory monocyte infiltration into the brain during acute virus infection. J Neuroinflammation. 2017;14(1):238.

75. Badshah $\mathrm{H}$, et al. Protective effect of lupeol against lipopolysaccharideinduced neuroinflammation via the $\mathrm{p38/ \textrm {c } - J u n ~ N - t e r m i n a l ~ k i n a s e ~ p a t h w a y ~ i n ~}$ the adult mouse brain. J Neurolmmune Pharmacol. 2016;11(1):48-60.

76. Papageorgiou IE, et al. TLR4-activated microglia require IFN-gamma to induce severe neuronal dysfunction and death in situ. Proc Natl Acad Sci U S A. 2016;113(1):212-7.

77. Luo J. The role of GSK3beta in the development of the central nervous system. Front Biol (Beijing). 2012;7(3):212-20.

78. Liu Y, et al. Overexpression of glycogen synthase kinase 3 beta sensitizes neuronal cells to ethanol toxicity. J Neurosci Res. 2009;87(12):2793-802.

79. Roy A, Kolattukudy PE. Monocyte chemotactic protein-induced protein (MCPIP) promotes inflammatory angiogenesis via sequential induction of oxidative stress, endoplasmic reticulum stress and autophagy. Cell Signal. 2012;24(11):2123-31.

80. Kim H-M, et al. CC chemokine receptor 2 inhibitor ameliorates hepatic steatosis by improving ER stress and inflammation in a type 2 diabetic mouse model. PLoS One. 2015;10(3):e0120711.

81. Yang F, Luo J. Endoplasmic reticulum stress and ethanol neurotoxicity. Biomolecules. 2015;5(4):2538-53.

82. Harper KM, et al. Age-related differences in anxiety-like behavior and amygdalar CCL2 responsiveness to stress following alcohol withdrawal in male Wistar rats. Psychopharmacology. 2017;234(1):79-88.

\section{Ready to submit your research? Choose BMC and benefit from:}

- fast, convenient online submission

- thorough peer review by experienced researchers in your field

- rapid publication on acceptance

- support for research data, including large and complex data types

- gold Open Access which fosters wider collaboration and increased citations

- maximum visibility for your research: over $100 \mathrm{M}$ website views per year

At BMC, research is always in progress.

Learn more biomedcentral.com/submissions 